\title{
Physiological condition of Balanus amphitrite cyprid larvae determines habitat selection success
}

\author{
Réjean Tremblay ${ }^{1,}{ }^{*}$, Frédéric Olivier $^{2}$, Edwin Bourget $^{3}$, Dan Rittschof $^{4}$ \\ ${ }^{1}$ Institut des sciences de la mer-Université du Québec à Rimouski, 310 allée des Ursulines, Rimouski, Québec G5L 3A1, Canada \\ ${ }^{2}$ Station Marine de Dinard USM 0404 (MNHN), Département Milieux et Peuplements Aquatiques, UMR 5178 BOME, \\ 17 avenue George V, BP 70134, 35801 Dinard Cedex, France \\ ${ }^{3}$ Vice-rectorat à la recherche, Pavillon central, Université de Sherbrooke, Sherbrooke, Québec J1K 2R1, Canada \\ ${ }^{4}$ Marine Laboratory, Nicholas School of the Environment, Earth and Ocean Sciences, Duke University, \\ 135 Duke Marine Laboratory Road, Beaufort, North Carolina 28516, USA
}

\begin{abstract}
A field experiment was used to assess the relationship between the physiological condition of barnacle larvae and habitat selectivity at settlement. Three experiments were carried out on methacrylate (Plexiglas) disks precolonized with biofilms of different ages $(0,7,14$ and $21 \mathrm{~d})$ that were arranged within 3 blocks and placed at 3 intertidal positions corresponding to the upper limit, mid zone and lower limit of the adult Balanus amphitrite (Darwin) habitat. To limit the effect of post-settlement mortality, each experiment was conducted over 2 full tidal cycles only. During these periods, larvae in the water column were sampled and abundance estimated at each high tide at the depths corresponding to the 3 intertidal positions. Larval physiological condition was assessed using lipid classes analyzed by liquid chromatography. Ratios of total triacylglycerols to sterol content (TAG/ST) were used to quantify the energy status of larvae. Our results indicate that the cyprids' TAG levels reflect the level of settlement success independent of cyprid abundance in the water column. Intertidal position and biofilm characteristics were significant factors determining the settlement success with respect to cyprid energy content. The number and the energy content of settling cyprids were maximal on clean surfaces and decreased gradually with the degree of biofilm precolonization. Our study shows (1) the importance of lipid levels, particularly TAG, in habitat discrimination at small temporal scales in B. amphitrite cyprids and (2) that larval energy content is a critical variable for understanding benthic-pelagic coupling.
\end{abstract}

KEY WORDS: Larvae · Settlement success · Physiological state $\cdot$ Lipid class $\cdot$ Biofilm $\cdot$ Habitat discrimination

Resale or republication not permitted without written consent of the publisher

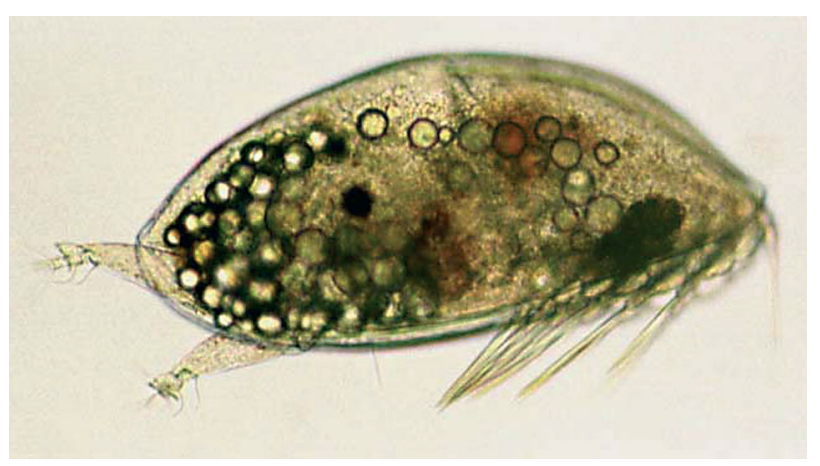

Cyprid larva of the barnacle Balanus amphitrite containing lipid droplets, its main energy reserve.

Photo: Réjean Tremblay

\section{INTRODUCTION}

Over $70 \%$ of benthic invertebrate species in temperate and tropical regions have a life cycle involving a planktonic dispersal phase (Thorson 1950). Larval drifting periods lasting from weeks to months promote the formation of large, homogeneous, randomly mating populations. This planktonic dispersion exposes larvae to high risks leading to mortalities well over $90 \%$ (Morgan 1995). Pelagic mortality has numerous causes, including physiological stress induced by environmental conditions (e.g. temperature, salinity, oxygen, UV; Pechenik et al. 1990), larval advection (Incze et al. 2000), predation (Navarrete \& Wieters 2000) and starvation (McEdward \& Qian 2001). In coastal waters, natural food resources are often thought to be too low to support larval growth and development (Paulay et 
al. 1985, Fenaux et al. 1994), but little information from field studies is available. Most information comes from laboratory experiments, particularly in the context of aquaculture (Pernet \& Tremblay 2004, Pernet et al. 2004). Thus, there is a large body of literature on the effects of a variety of factors on larval metabolism and survival in laboratory experiments, but there is very little information from in situ studies (but see Navarrete \& Wieters 2000, Jarrett 2003).

For benthic species, the pelagic phase ends when attachment occurs. The transition from a pelagic to a benthic mode of life implies a period of habitat selection by the larvae (Miron et al. 2000). For barnacles, the success of this transition depends on the availability of stored energy sufficient to sustain the high energy demands of the non-feeding cyprid stage (Pechenik et al. 1998). The final attachment of cyprids occurs after the active selection of a microhabitat (Walters et al. 1999). Since cyprids do not feed, the energetic reserves accumulated during the naupliar stages are important, as demonstrated by Hentschel \& Emlet (2000). Energy accumulated during the naupliar stages affects the larva's capacity to locate a substratum and to settle and metamorphose successfully (Jarrett \& Pechenik 1997, Miron et al. 2000, Jarrett 2003). Balanus amphitrite (Darwin) cyprids lose their settlement selectivity with age (Rittschof et al. 1984), a phenomenon tentatively explained by the 'desperate larva hypothesis' (Toonen \& Pawlik 1994). During metamorphosis, neutral lipids, particularly triacylglycerol (TAG), are the primary source of energetic reserves used by marine invertebrate larvae (Lucas et al. 1979, Pernet et al. 2003). For instance, in the mussel Mytilus edulis larval survival during the settlement period was positively correlated with the TAG content of premetamorphosed larvae, which explained $28 \%$ of the variance in settlement success (Pernet et al. 2004). In B. amphitrite, a strong positive correlation between the TAG/DNA ratio of cyprid stages and percent metamorphosis has been shown (Thiyagarajan et al. 2002).

Using a field experiment designed to study habitat selectivity, Olivier et al. (2000) observed a positive correlation between Balanus ampitrite cyprid settlement and the nature of the biofilm on the settlement surface, with settling mainly occurring on surfaces free of detritus. Furthermore, these authors showed a significant decrease in cyprid settlement success with successive experiments over $6 d_{\text {; }}$ this decrease was associated with a loss of habitat selectivity. An analysis of the physiological condition of these cyprids, representing their energy content and age, would be an interesting opportunity to demonstrate the role of larval physiology in controlling the habitat selection behaviour leading to permanent attachment in the field. Thus, in this study, we analyzed the energy status of cyprids collected during this earlier experiment (Olivier et al. 2000) to test the hypothesis that habitat selectivity and settlement success relies more on the physiological condition of the larvae rather than on the supply of larvae. The physiological condition of the larvae was examined in relation to the abundance of both nonsettled and settled larvae, substrata of different quality and intertidal position.

\section{MATERIALS AND METHODS}

Experimental design. Balanus amphitrite cyprids, which were analyzed for lipid class content as a measure of their energy status, were collected during an experiment conducted by Olivier et al. (2000). The Olivier et al. (2000) study was carried out under the Duke University Marine Laboratory (DUML) dock on Pivers Island (Beaufort, North Carolina, USA; $34^{\circ} 43^{\prime} 03^{\prime \prime} \mathrm{N}, 76^{\circ} 40^{\prime} 18^{\prime \prime} \mathrm{W}$ ) in April 1998. This site is characterized by the presence of several barnacle species, but in April only B. amphitrite recruit (Holm 1990, Roberts et al. 1991). Three experiments taking place over $6 \mathrm{~d}$ assessed the relative roles of larval supply, biofilm composition (intertidal position and age) and tidal height during cyprid settlement. As presented in Fig. 1 of Olivier et al. (2000), 3 sets of 3 Plexiglas sheets $(1.22 \times 1.22 \mathrm{~m})$, named 'block' in this design, were secured under the DUML dock $1 \mathrm{~d}$ before the beginning of an experiment at 3 intertidal positions, high $(\mathrm{H})$, medium (M) and low (L). Each experimental block had been sandblasted (40 $\mu \mathrm{m}$ grit) to create homogeneous rugosity suitable for barnacle settlement and 12 holes were cut by laser beam (Mazak laser $2000 \mathrm{~W}$ ) providing 12 disks of $20.32 \mathrm{~cm}$ diameter (area $324.3 \mathrm{~cm}^{2}$ ). Each disk was was considered a cell in the experimental design. Prior to the start of the experiment, 3 sets of fouling community films of $7,14,21 \mathrm{~d}$ were obtained by placing 9 sets of 27 disks at the 3 predetermined intertidal positions ( 3 sets/intertidal position). At the beginning of each experiment, precolonized disks corresponding to the 3 intertidal origins $\left(\mathrm{O}_{\mathrm{H}}, \mathrm{O}_{\mathrm{M}}, \mathrm{O}_{\mathrm{L}}\right)$ and 4 levels of biofilm colonization $0,7,14$ and $21 \mathrm{~d}$ were randomly arranged within the blocks so that each block included 12 disks corresponding to the 3 intertidal positions $\left(\mathrm{O}_{\mathrm{H}}, \mathrm{O}_{\mathrm{M}}, \mathrm{O}_{\mathrm{L}}\right)$ and 4 ages of biofilm $(0,7$, 14, $21 \mathrm{~d})$. Three blocks were installed at each intertidal position. Cyprid habitat selection was studied using disks precolonized at various intertidal positions for different durations to obtain a biofilm abundance gradient. Before starting experiments, all biofilm surfaces were closely examined and no settlers were observed. See Olivier et al. (2000) for more details.

Three successive experiments were carried out to assess the variability in Balanus amphitrite settlement 
according to (1) variations in larval supply (larval density in the water column) and (2) differences in the energy levels of the larval population. By conducting 3 successive experiments over a 6 d period (23 to 28 April), we expected the cyprid larvae in the water column to be in different physiological conditions and to have different responses to the biofouled surfaces. At the end of each barnacle settlement experiment, each lasting 2 tidal cycles ( 2 immersion periods) to limit the effect of post-settlement mortality, all disks were quickly and carefully removed from the holders and transferred to running seawater aquaria at DUML. In the laboratory, the settled larvae were collected using a binocular microscope, counted and then stored at $-80^{\circ} \mathrm{C}$ prior to lipid analyses.

Larval supply. During the 3 experiments, plankton samples were collected at high slack tide through an $80 \mu \mathrm{m}$ mesh Nitex net for 2 min using a self-priming centrifugal pump (Monarch BSGF-8, Type A). Three replicate water samples of 9231 each were filtered from the northern side of the pier for each depth, corresponding to the high, medium and low experimental disk intertidal position. Each sample was immediately sorted to collect 20 live cyprids that were immediately placed at $-80^{\circ} \mathrm{C}$ for physiological condition determinations.

Physiological conditions. Neutral lipids were extracted based on protocols described in Ouellet \& Taggart (1992) in the first 6 mo after collection. Individual cyprids were homogenized with a glass pestle in $500 \mu \mathrm{l}$ of chloroform-methanol (2:1, v/v) on ice and, dependent on availability, 6 to 15 individuals were analysed by treatment. The homogenate was rinsed with $\mathrm{KCl}$ solution $(0.88 \%)$ to obtain $\mathrm{CH}_{2} \mathrm{Cl}_{2}-\mathrm{CH}_{3} \mathrm{OH}-\mathrm{KCl}$ (2:1:0.6, by vol.; Folch et al. 1957). The homogenates were mixed and centrifuged twice at $4000 \mathrm{rpm}$ $(1500 \times g)$ for $2 \mathrm{~min}$ to cause phase separation. The lipid fraction (lower phase) was removed after each wash and transferred to a clean tube. We added $10 \mu \mathrm{g}$ of hexadecanone, an ethyl ketone, as an internal standard (Parrish \& Ackman 1985). The solvent was evaporated under nitrogen and lipids were resuspended in $20 \mu$ of chloroform. The entire sample was spotted onto S-III Chromarods (Iatron Laboratories) using a Hamilton syringe. The rods were initially developed for $30 \mathrm{~min}$ in hexane-ethyl ether-formic acid (82:2.5: 0.045 , by vol.), allowing separation of the ketone. Each rod was secondarily developed for $30 \mathrm{~min}$ in hexaneethyl ether-formic acid (55:29.7:0.075, by vol.) for separation of the TAG, free fatty acids (FFA) and free sterols (ST). Between each development, Chromarods were scanned by the flame ionization detection system (FID) of the Iatroscan Mark-V analyzer (Iatron Laboratories). Lipid classes were identified and quantified using the standard calibration curves obtained for each lipid class (Parrish \& Ackman 1985). Within each set of rods, we included one lipid standard and one extraction blank. TAG content can be related to larval physiological condition if TAG content is corrected for larval size. As there is a positive correlation between sterol content and size (Fraser 1989), we used the TAG/ST ratio to correct for size and to quantify larval energy stores. This correction factor has been previously applied to shrimp (Ouellet \& Taggart 1992) and bivalve (Pernet et al. 2003) larvae.

Data analysis. As described in Olivier et al. (2000), 2-way ANOVA was used to examine the effects of intertidal position and the experimental date on physiological conditions (TAG and ST contents, TAG/ST ratio) and on cyprid abundance in the water column (larval supply) over the $6 \mathrm{~d}$ experimental period $(\mathrm{n}=$ 54). All physiological results are news in this study and never presented in Olivier et al. (2000). Data for abundance and TAG/ST ratio were normalized using log transformations. Least-square means tests (LS means, SAS 1988) were adopted for post-hoc comparisons corrected for the total number of comparisons. Two-way ANOVA was used to examine the variability of settled larvae among experiments in relation to intertidal position following post-hoc LS means comparisons. Finally, we used split-split-plot factorial ANOVAs to analyze the effect of the biofilm origin and degree of periphyton colonization on the physiological condition and density of newly settled cyprids at the 3 intertidal positions for each settlement experiment. All the experimental data sets had a factor origin $\left(\mathrm{O}_{\mathrm{H}}, \mathrm{O}_{\mathrm{M}}\right.$ and $\left.\mathrm{O}_{\mathrm{L}}\right)$ and a factor age of biofilm $(0,7,14$ and $21 \mathrm{~d})$, thereby generating 12 different treatments ( 3 origins $\times 4$ ages)

\section{RESULTS}

\section{Larval supply and physiological condition}

As described in Olivier et al. (2000), cyprid concentration in the water column varied significantly during the experimental period $(F=10.65, \mathrm{p}<0.001)$, reaching a maximum during Expt 3 ; there was no significant difference between Expts 1 and 2. Furthermore, no significant variation in cyprid abundance was observed vertically in the water column except in Expt 3 between the high and low positions (Fig. 1a). The physiological condition of cyprids from the water column, measured on 15 individuals per treatment, varied among the 3 experiments $(F=28.29$, p $<0.0001)$, with the highest TAG/ST ratios found during Expt 1. Cyprids from Expts 2 and 3 had similar TAG/ST ratios (Fig. 1b). The significant differences in the TAG/ST ratios were related to variability in the TAG content $(F=21.66, \mathrm{p}<0.0001 ;$ Fig. 1c). No significant differences were observed for ST content $(F=1.14, \mathrm{p}=0.38$; 


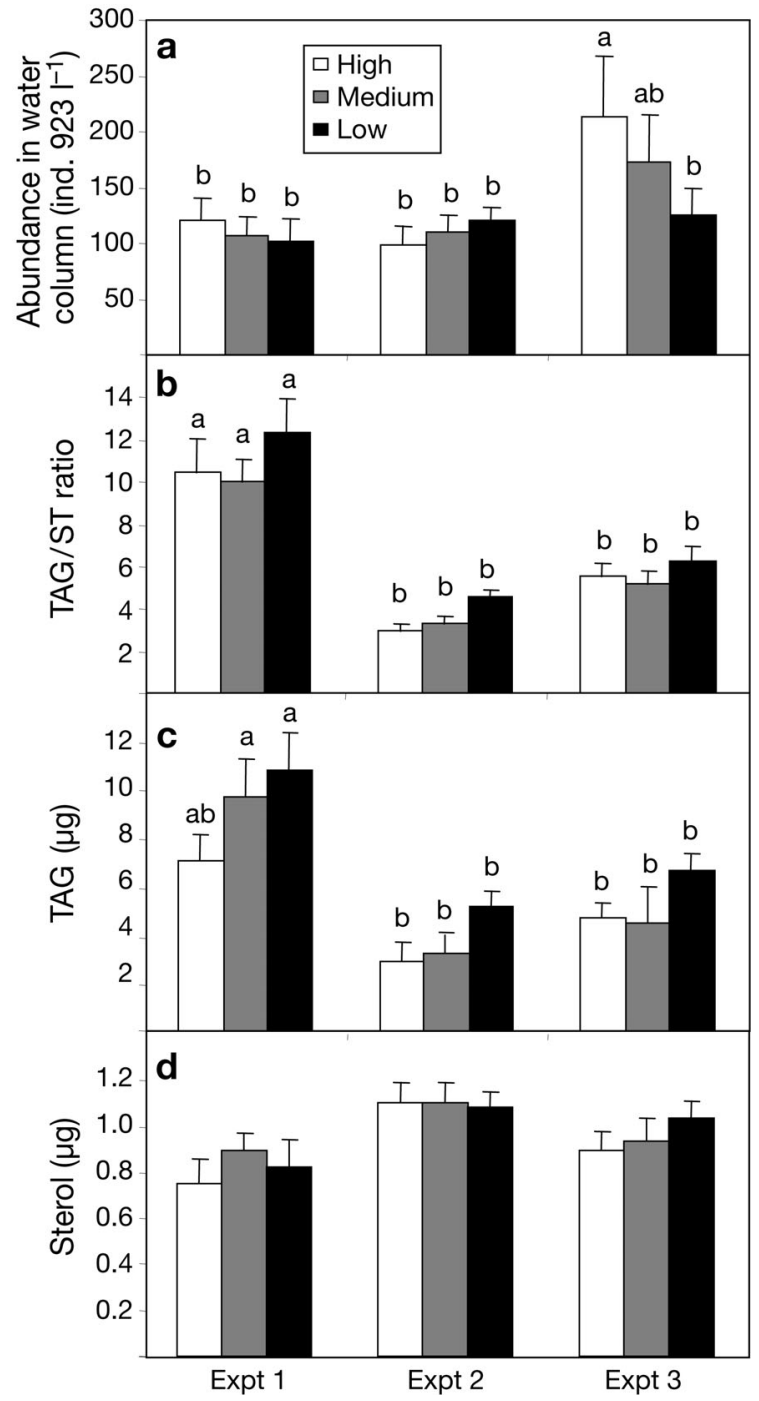

Fig. 1. Balanus amphitrite. Abundance and quality of cyprid larvae in the water column: mean (+SE) (a) abundance, (b) triacylglycerol (TAG) to sterol (ST) ratio, (c) TAG and (d) ST content. Cyprid larvae were sampled at the high tide slack water at the 3 intertidal depths (high, medium, low) for each of the 3 experiments. Different letters indicate significant differences.

(a) is identical to Fig. 5 in Olivier et al. (2000)

Fig. 1d). FFA made up less than $5 \%$ of the total lipids and showed no significant variability among treatments $(F=0.71, p=0.77)$. The physiological conditions of cyprid larvae did not vary significantly according to the larva's vertical distribution in the water column (TAG/ ST ratio: $F=0.26, \mathrm{p}=0.78$; TAG: $F=1.85, \mathrm{p}=0.16$ ).

\section{Settlement experiments}

One-way ANOVA showed that the number of postlarvae varied during the experimental period (Fig. 2; $F=14.916, \mathrm{p}<0.001$ ), with the highest value found

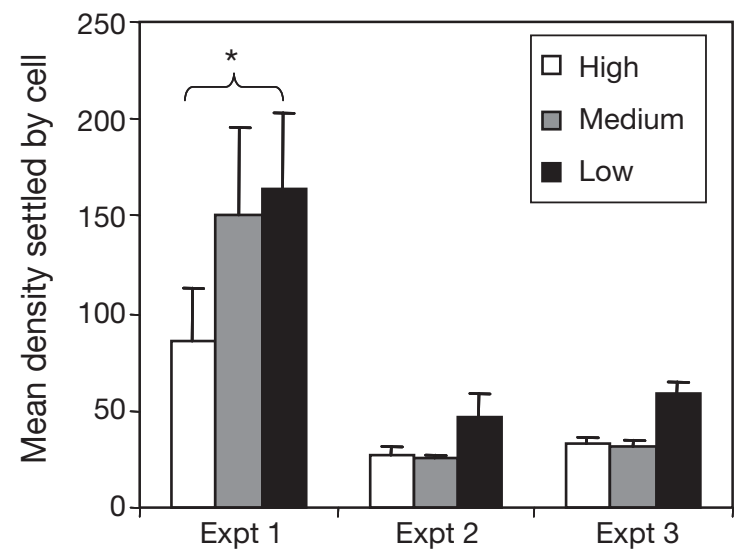

Fig. 2. Balanus amphitrite. Overall settlement (mean $+\mathrm{SE}$ ) of cyprid larvae for the 3 experiments in relation to intertidal depths. Biofilm type was not considered. ${ }^{*}$ Significant differences

in Expt 1 ( $\mathrm{p}<0.001)$. Overall larval settlement was reduced by a factor of 4 in Expts 2 and 3 (Fig. 2). The physiological conditions of post-larvae were characterized only for Expt 1; the scarcity of settled larvae in Expts 2 and 3, particularly in old biofilm (14 and $21 \mathrm{~d}$ ) and high tidal level precluded statistical analyses. Thus, we focused on cyprids from Expt 1 to examine the relationship between physiological condition $\mathrm{s}$ and substrate selectivity. As described in Olivier et al. (2000), the number of larvae settling over 2 tidal cycles was highest on the clean surfaces and decreased gradually with the degree of periphyton precolonization. The number of settled larvae was also influenced by intertidal position (Fig. 3a; $F=80.85, p<0.0001$ ). For the $0 \mathrm{~d}$ and $7 \mathrm{~d}$ biofilms, larval abundance was significantly lower at the $H$ than at the $M$ and $L$ intertidal position. No differences were observed for the number of larvae settled on the $14 \mathrm{~d}$ and the $21 \mathrm{~d}$ biofilms. Settled larvae were most abundant on the $0 \mathrm{~d}$ disks at all intertidal positions. Settlement was not related to the intertidal origin of the biofilm $(F=2.21, \mathrm{p}=0.119)$.

We observed variability in the TAG content and the TAG/ST ratio. As was the case with the abundance of newly settled cyprids, the TAG/ST ratios were higher in individuals sampled on disks with no periphyton colonization (Table 1, Fig. 3b). The TAG/ST ratios of settled larvae were higher at 0 d compared to all other biofilm ages (LS means, $\mathrm{p}<0.05$ ). No effect of intertidal position, origin or block was observed. The variability of the TAG/ST ratio was related to the TAG content (Table 1, Fig. 3c), with higher values of TAG content found on the $0 \mathrm{~d}$ biofilms (LS means, $\mathrm{p}<0.05$ ). For ST, no significant variability of factor effects was observed (Table 1). For FFA, the levels observed were low below the detection limits for many samples, preventing statistical analyses. 


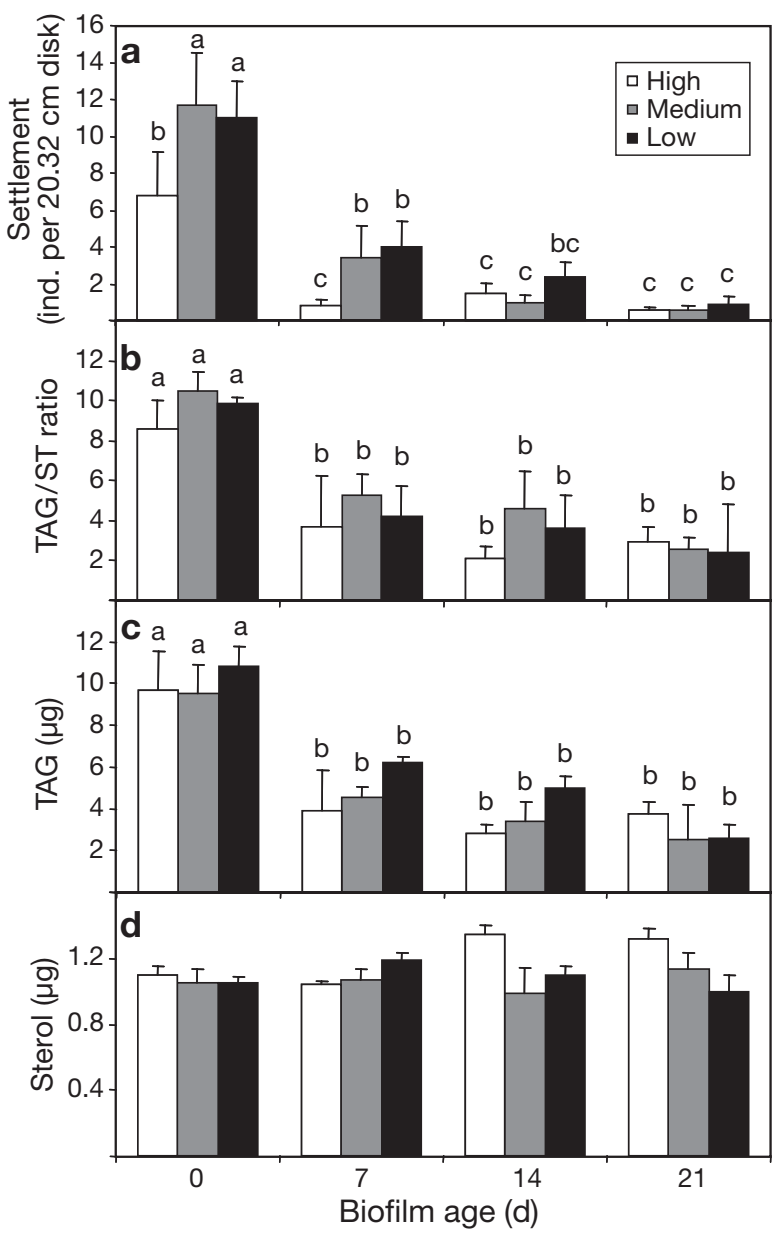

Fig. 3. Balanus amphitrite. Post-larvae settlement in relation to biofilm age: mean (+SE) (a) number of new settlers at the end of the first experiment on biofilms of different ages, (b) triacylglycerol (TAG) to sterol (ST) ratio, (c) TAG and (d) ST content. Post-larvae were sampled at the high tide slack water at the 3 intertidal depths (high, medium, low). Different letters indicate significant differences

\section{DISCUSSION}

Our integrative study confirms the hypotheses that physiological conditions of Balanus amphitrite cyprid larvae significantly influence settlement success. As in the study of Jarrett \& Pechenik (1997), we observed, in field conditions, variability of physiological conditions and energy content between different cyprid cohorts. However, to our knowledge, our results are the first to show clearly that physiological condition controlled habitat selection behaviour.

\section{Larval supply and settlement}

Olivier et al. (2000) observed no correlation between larval supply and the intensity of settlement at
Table 1. Balanus amphitrite. Results of the split-split-plot ANOVA examining the effects of block, position (intertidal position of the experimental disks: High, Medium, Low), origin (intertidal position of biofilm precolonization: $\mathrm{O}_{\text {High }}, \mathrm{O}_{\text {Medium, }}$ $\mathrm{O}_{\text {Low }}$ ) and age (degree of biofilm precolonization: 0, 7, 14, $21 \mathrm{~d}$ ) on the triacylglycerol/sterol (TAG/ST) ratio, TAG content, and ST content of newly settled cyprids in the first settlement experiment. Significant effects are indicated in bold

\begin{tabular}{|lccccc|}
\hline Source of variation & SS & df & MS & $F$ & $\mathrm{p}$ \\
\hline TAG/ST ratio & & & & & \\
Block & 10.15 & 2 & 5.07 & 0.792 & 0.464 \\
Position & 3.95 & 2 & 1.97 & 0.309 & 0.737 \\
Block $\times$ Position & 61.47 & 4 & 15.36 & 2.41 & 0.083 \\
Origin & 2.60 & 2 & 1.30 & 0.204 & 0.816 \\
Age & 481.3 & 3 & 160.4 & 25.16 & $<\mathbf{0 . 0 0 1}$ \\
Origin $\times$ Age & 7.80 & 4 & 1.95 & 0.305 & 0.870 \\
Position $\times$ Origin & 10.57 & 4 & 2.64 & 0.414 & 0.795 \\
Position $\times$ Age & 14.37 & 6 & 2.39 & 0.375 & 0.885 \\
Position $\times$ Origin $\times$ Age & 9.78 & 8 & 1.34 & 0.576 & 0.479 \\
TAG content & & & & & \\
Block & 8.52 & 2 & 4.26 & 0.177 & 0.839 \\
Position & 69.76 & 2 & 34.88 & 1.45 & 0.258 \\
Block $\times$ Position & 223.2 & 4 & 55.79 & 2.32 & 0.092 \\
Origin & 30.53 & 2 & 15.27 & 0.635 & 0.540 \\
Age & 1976 & 3 & 658.9 & 27.42 & $<\mathbf{0 . 0 0 1}$ \\
Origin $\times$ Age & 41.59 & 4 & 10.40 & 0.432 & 0.780 \\
Position $\times$ Origin & 46.30 & 4 & 11.58 & 0.481 & 0.749 \\
Position $\times$ Age & 108.8 & 6 & 18.14 & 0.755 & 0.613 \\
Position $\times$ Origin $\times$ Age & 7.5 & 8 & 7.49 & 0.312 & 0.582 \\
ST content & & & & & \\
Block & 1.57 & 2 & 0.778 & 1.21 & 0.317 \\
Position & 0.856 & 2 & 0.428 & 0.668 & 0.523 \\
Block $\times$ Position & 3.82 & 4 & 0.955 & 1.49 & 0.242 \\
Origin & 0.511 & 2 & 0.255 & 0.398 & 0.676 \\
Age & 4.26 & 3 & 1.41 & 2.21 & 0.118 \\
Origin $\times$ Age & 1.19 & 4 & 0.297 & 0.464 & 0.760 \\
Position $\times$ Origin & 2.49 & 4 & 0.624 & 0.974 & 0.443 \\
Position $\times$ Age & 6.33 & 6 & 1.05 & 1.64 & 0.186 \\
Position $\times$ Origin $\times$ Age & 2.78 & 8 & 0.027 & 0.043 & 0.837 \\
\hline & & & & & \\
\hline
\end{tabular}

the short-term scale of $1 \mathrm{wk}$. As discussed by those authors, the flux of larvae to the substratum is related to the flow velocities and care was taken in the present study to conduct repeated experiments. Current velocity patterns were comparable among experiments and were strongly related to tidal cycle, as presented in Olivier et al. (2000). Larval concentrations in the water column did not vary during the first 2 experiments, whereas the densities of newly settled cyprids decreased significantly and drastically. Larval supply was maximal during the third experiment, but settlement was identical to the previous 2 experiments (Olivier et al. 2000). Since the physical variables measured during the experimental period were stable, we propose that the weak correlation observed between larval supply and larval settlement could be related to a shift in the cyprid's overall capacity to discriminate surface quality. 
The metamorphosis of cyprid barnacles to juveniles is an energetically expensive process, requiring up to $30 \%$ of the organic carbon reserves (Lucas et al. 1979). A storage protein known as Cyprid Major Protein (CMP), which is biochemically and immunologically similar to vitellin, has been identified in Balanus amphitrite (Shimizu et al. 1996). These authors observed that CMP was most abundant in cyprids and abruptly decreased in quantity following metamorphosis to the juvenile stage. Satuito et al. (1996) suggested that cyprids use this storage protein (CMP) mainly for the production of juvenile protein structures during metamorphosis. Thus, the decrease in settlement success may occur when CMP levels have been depleted to the point where the production of juvenile protein structures required during metamorphosis cannot be supported. Following this hypothesis, a delay in the metamorphosis of cyprid larvae could result in poorer settlement and metamorphosis success due to a reduction in biochemical components, such as CMP (Satuito et al. 1997) and lipids (Lucas et al. 1979, Rittschof et al. 1984), to quantities insufficient to produce cellular structures essential to metamorphosis. Our results are consistent with this theory. Thus, the cyprid larvae in Expt 1, which showed highest settlement, had the most abundant lipid reserves, as indicated by the high TAG level content and high TAG/ST ratio. Neutral lipids, particularly TAG, are the main energetic reserves used by marine invertebrate larvae (Pernet et al. 2003). In the other 2 experiments, which were characterized by low settlement, the TAG content and TAG/ST ratio decreased significantly. Thus, in $B$. amphitrite, the TAG level in cyprids appears to be reflected in the level of settlement success independent of the density of cyprids in the water column. Jarrett (2003) obtained similar results in both laboratory and field studies. He observed a threshold energetic level of approximately $13 \mu \mathrm{g}$ total carbon (including lipids, proteins and carbohydrates) in Semibalanus balanoides cyprids above which metamorphosis was not compromised. Below this value, however, settlement and metamorphosis success were reduced. However, in our study we could not establish a relationship with metamorphosis success, as many of the settlers collected were cemented to the surface, but had not yet metamorphosed.

In Expt 3, the larval supply was higher than during the other 2 experiments but the TAG content was low, possibly too low to generate a high settlement success. These results could be related to the advection of a new cohort of larvae. The periodic transport of large numbers of larvae by water flow is a well-documented phenomenon (Drouin et al. 2002). Jarrett \& Pechenik (1997) have already observed important differences in the physiological quality of barnacle post-larvae from different cohorts. These physiological variations ob- served among cohorts may have resulted from the influence of several factors, such as variability of nutritional conditions during larval ontogeny (Hentschel \& Emlet 2000), effects of delayed settlement on cyprid energy content (Lucas et al. 1979) and/or have a genetic basis (recruitment from different geographic populations or larvae produced from genetically different adults within a single population).

\section{Intertidal position and biofilm}

In our study, intertidal position and biofilm characteristics were significant factors in determining the vertical patterns of the newly settled cyprids during the first experiment. At the cyprid stage, a barnacle is able to settle and metamorphose and above all, to explore the substratum to select the best habitat for juvenile and adult development in response to environmental cues (Rittschof et al. 1984, Roberts et al. 1991, Walters et al. 1999). The local hydrodynamic conditions are significant factors in the transfer of larvae from the planktonic phase to initial adhesion on the surface (Jonsson et al. 2004) and for the postsettlement growth and survival (Larsson \& Jonsson 2006). In the intertidal zone, the exploration of substratum by cyprids is correlated with height on the shore, a variable directly related to the duration of immersion (Miron et al. 1995). Thus, at medium and low intertidal positions, cyprids had more time to explore the substratum, which would allow the larvae in better physiological condition to find an appropriate substratum and habitat. Thus, the significant relation between the short-term vertical patterns of larvae in the water column and the short-term vertical patterns of settlement are in agreement with the supply-side theory (Underwood \& Fairweather 1989, Olivier et al. 2000). In contrast, the longer-term (i.e. over the 3 experiments) results do not support the supply-side theory. Indeed, even when the density of cyprids in the water column increased (e.g. Expt 3), the settlement success remained low. Over the $6 \mathrm{~d}$ experimental period, the physiological conditions of cyprids in the water column better explained the settlement pattern than did larval supply.

The relative importance of the physical and biological factors in governing settlement processes has been widely debated. Many cues have been identified, including salinity, temperature, light, water flow, substrate characteristics, pheromones, juvenile hormones and the presence of conspecific adults (Satuito et al. 1996, Miron et al. 2000). Our study clearly shows that in Balanus amphitrite, biological cues related to the presence of natural biofilms play an important role in determining the suitability of a particular settlement 
site. To assess the role of biofilm colonization on the settlement of cyprids in the field, we conducted experiments limiting the interaction of this factor with others factors. Three experiments were conducted over a short period ( 6 d) to obtain comparable fluctuations of temperature, salinity, water velocity and light as described in Olivier et al. (2000). The number and physiological condition, as characterized by the TAG level, of larvae that settled during the 2 tidal cycles was maximal on the clean surfaces and decreased gradually with the degree of periphyton precolonization. These results show that $B$. amphitrite cyprid larvae with high energetic reserves preferred clean surfaces. However, when TAG lipid reserves decreased, cyprids seemed to risk settlement in poorer quality sites rather than postpone settling. Thus, when TAG levels and TAG/ST ratios decline, both settlement intensity and settlement choice decline, suggesting that our results confirm the 'desperate larva hypothesis' (Toonen \& Pawlik 1994), where cyprids lose their settlement selectivity with age. The origin of the biofouled surfaces $(H, M, L)$ did not affect the density or the physiological condition of the newly settled $B$. amphitrite cyprids, suggesting a lack of discrimination for a specific intertidal position in contrast to Semibalanus balanoides cyprids (Miron et al. 1995).

For cyprids to settle when their energy content is high is not only a means to increase metamorphosis success but also to increase juvenile growth potential and thus juvenile performance (Jarrett 2003, Thiyagarajan et al. 2005, Emlet \& Sadro 2006). The effect of cyprid energetic reserves on juvenile growth has been detected up to $12 \mathrm{~d}$ after settlement (Jarrett \& Pechenik 1997, Thiyagarajan et al. 2003). Since the first few days of post-metamorphosis are generally considered to be critical, the physiological condition of larvae before settlement is likely significant for recruitment (Gosselin \& Qian 1997).

\section{CONCLUSIONS}

Our study shows that the energetic reserves in cyprid larvae vary considerably among cohorts. Specifically, we show that the success of Balanus amphitrite settlement is related not only to larval supply, but also to the physiological state of larvae. Thus, our results emphasize the importance of larval physiology in controlling habitat selection behaviour leading to permanent attachment.

Acknowledgements. Funding of this research was provided by NSERC and FCAR grants to E.B. and by post-doctoral fellowships to F.O. from the Regional Council of Brittany (France) and the Ministry of Education of Quebec. We are grateful to Dr. S. Conova for valuable help in the field and to L. Lapointe, Dr. F. Guichard, Dr. P. Archambault and Dr. G. Miron for their constructive and critical discussions. Thanks are also addressed to G. Daigle, Département de mathémathiques et statistique, Université Laval, for validating the statistical models used in this study.

\section{LITERATURE CITED}

Drouin CA, Bourget E, Tremblay R (2002) Larval transport processes of barnacle larvae in the vicinity of the interface between two genetically different populations of Semibalanus balanoides. Mar Ecol Prog Ser 229:165-172

Emlet RB, Sadro SS (2006) Linking stages of life history: how larval quality translates into juvenile performance for an intertidal barnacle (Balanus glandula). Integ Comp Biol 46:334-346

Fenaux L, Strathmann MF, Strathmann RR (1994) 5 tests of food-limited growth of larvae in coastal waters by comparisons of rates of development and form of Echinoplutei. Limnol Oceanogr 39:84-98

Folch J, Lees M, Sloane-Stanley GH (1957) A simple method for the isolation and purification of total lipids from animal tissues. J Biol Chem 226:497

Fraser AJ (1989) Triacylglycerol content as a condition index for fish, bivalve, and crustacean larvae. Can J Fish Aquat Sci 46:1868-1873

Gosselin LA, Qian PY (1997) Juvenile mortality in benthic marine invertebrates. Mar Ecol Prog Ser 146:265-282

Hentschel BT, Emlet RB (2000) Metamorphosis of barnacle nauplii: effects of food variability and a comparison with amphibian models. Ecology 81:3495-3508

Holm E (1990) Settlement site choice in the barnacle Balanus amphitrite: demographic and evolutionary consequences. PhD dissertation, Duke University, Durham, NC

Incze LS, Wahle RA, Palma AT (2000) Advection and settlement rates in a benthic invertebrate: recruitment to first benthic stage in Homarus americanus. ICES J Mar Sci 57: $430-437$

Jarrett JN (2003) Seasonal variation in larval condition and postsettlement performance of the barnacle Semibalanus balanoides. Ecology 84:384-390

Jarrett JN, Pechenik JA (1997) Temporal variation in cyprid quality and juvenile growth capacity for an interdidal barnacle. Ecology 78:1262-1265. Erratum in Ecology 78: 1944-1944

Jonsson PR, Berntsson KM, Larsson AI (2004) Linking larval supply to recruitment: flow-mediated control of initial adhesion of barnacle larvae. Ecology 85:2850-2859

Larsson AI, Jonsson PR (2006) Barnacle larvae actively select flow environments supporting post-settlement growth and survival. Ecology 87:1960-1966

Lucas MI, Walker G, Holland DL, Crisp DJ (1979) An energy budget for the free-swimming and metamorphosing larvae of Balanus balanoides (Crustacea: Cirripedia). Mar Biol 55:221-229

McEdward LR, Qian PY (2001) Effects of the duration and timing of starvation during larval life on the metamorphosis and initial juvenile size of the polychaete Hydroides elegans (Haswell). J Exp Mar Biol Ecol 261:185-197

Miron G, Boudreau B, Bourget E (1995) Use of larval supply in benthic ecology: testing correlations between larval supply and larval settlement. Mar Ecol Prog Ser 124:301-305

Miron G, Walters LJ, Tremblay R, Bourget E (2000) Physiological condition and larval behavior of barnacles: a preliminary look at the relationship between TAG/DNA ratio 
and larval substratum exploration in Balanus amphitrite. Mar Ecol Prog Ser 198:303-310

Morgan S (1995) Life and death in the plankton: larval mortality and adaptation. In: McEdward L (ed) Ecology of marine invertebrate larvae. CRC Press, Boca Raton, FL, p 279-322

Navarrete SA, Wieters EA (2000) Variation in barnacle recruitment over small scales: larval predation by adults and maintenance of community pattern. J Exp Mar Biol Ecol 253:131148

Olivier F, Tremblay R, Bourget E, Rittschof D (2000) Barnacle settlement: field experiments on the influence of larval supply, tidal level, biofilm quality and age of Balanus amphitrite cyprids. Mar Ecol Prog Ser 199:185-204

Ouellet P, Taggart CT (1992) Lipid condition and survival in shrimp (Pandalus borealis) larvae. Can J Fish Aquat Sci 49:368-378

Parrish CC, Ackman RG (1985) Calibration of the IatroscanChromarod system for marine lipid class analyses. Lipids 20:521-530

Paulay G, Boring L, Strathmann RR (1985) Food limited growth and development of larvae: experiments with natural sea water. J Exp Mar Biol Ecol 93:1-10

Pechenik JA, Eyster LS, Widdows J, Bayne BL (1990) The influence of food concentration and temperature on growth and morphological differentiation of blue mussel Mytilus edulis L. larvae. J Exp Mar Biol Ecol 136:47-64

Pechenik JA, Wendt DE, Jarrett JN (1998) Metamorphosis is not a new beginning: larval experience influences juvenile performance. BioScience 48:901-909

Pernet F, Tremblay R (2004) Effect of varying levels of dietary essential fatty acid during early ontogeny of the sea scallop Placopecten magellanicus. J Exp Mar Biol Ecol 310:73-86

Pernet F, Tremblay R, Bourget E (2003) Biochemical indicator of sea scallop (Placopecten magellanicus) quality based on lipid class composition. Part II. Larval growth, competency and settlement. J Shellfish Res 22:377-388

Pernet F, Tremblay R, Langdon C, Bourget E (2004) Effect of additions of dietary triacylglycerol microspheres on growth, survival, and settlement of mussel (Mytilus sp.) larvae. Mar Biol 144:693-703

Rittschof D, Branscomb ES, Costlow JD (1984) Settlement and

Editorial responsibility: Otto Kinne (Editor-in-Chief), Oldendorf/Luhe, Germany behavior in relation to flow and surface in larval barnacles, Balanus amphithrite Darwin. J Exp Mar Biol Ecol 82: 131-146

Roberts D, Rittschof D, Holm E, Schmidt AR (1991) Factors influencing initial larval settlement: temporal, spatial and surface molecular components. J Exp Mar Biol Ecol 150: 203-221

SAS Institute (1988) SAS language guide for personal computers, 6.03 edn. SAS Institute, Cary, NC

Satuito CG, Shimizu K, Natoyama K, Yamazaki M, Fusetani N (1996) Age-related settlement success by cyprids of the barnacle Balanus amphitrite, with special reference to consumption of cyprid storage protein. Mar Biol 127: $125-130$

Satuito CG, Shimizu K, Fusetani N (1997) Studies on the factors influencing larval settlement in Balanus amphitrite and Mytilus galloprovincialis. Hydrobiologia 358:275-280

Shimizu K, Saikawa W, Fusetani N (1996) Identification and partial characterization of vitellin from the barnacle Balanus amphitrite. Comp Biochem Physiol 115B:111-119

Thiyagarajan V, Harder T, Qian PY (2002) Relationship between cyprid energy reserves and metamorphosis in the barnacle Balanus amphitrite Darwin (Cirripedia; Thoracica). J Exp Mar Biol Ecol 280:79-93

Thiyagarajan V, Harder T, Qian PY (2003) Effects of TAG/ DNA ratio and age of cyprids on post-metamorphic growth and survival in the barnacle Balanus amphitrite. J Mar Biol Assoc UK 83:83-88

Thiyagarajan V, Hung OS, Chiu JMY, Wu RSS, Qian PY (2005) Growth and survival of juvenile barnacle Balanus amphitrite: interactive effects of cyprid energy reserve and habitat. Mar Ecol Prog Ser 299:229-237

Thorson G (1950) Reproductive and larval ecology of marine bottom invertebrates. Biol Rev 25:1-45

Toonen RJ, Pawlik JR (1994) Foundations of gregariousness. Nature 370:511-512

Underwood AJ, Fairweather PG (1989) Supply-side ecology and benthic marine assemblages. Trends Ecol Evol 4: $16-20$

Walters LJ, Miron G, Bourget E (1999) Endoscopic observations of invertebrate larval substratum exploration and settlement. Mar Ecol Prog Ser 182:95-108

Submitted: January 17, 2007; Accepted: May 10, 2007

Proofs received from author(s): June 5, 2007 